\title{
O financiamento da educação a partir do Plano de Ações Articuladas (PAR) em municípios paraenses: regime de colaboração?
}

\author{
Education funding on municipalities of Pará through the Articulated Actions \\ Plan (PAR): collaboration regime? \\ La financiación de la educación desde el Plan de Acciónes Articuladas (PAR) \\ em las ciudades de pará: ¿régimen de colaboración?
}

DALVA VALENTE GUIMARÃES GUTIERRES ROSANA MARIA GEMAQUE ROLIM

\begin{abstract}
Resumo: $\mathrm{O}$ artigo trata do financiamento da educação no contexto do Plano de Ações Articuladas (PAR) nos municípios de Altamira, Barcarena, Belém, Cametá e Castanhal, de 2010 a 2014, na perspectiva de dimensionar a responsabilidade dos entes federativos na efetivação do regime de colaboração. Como procedimento metodológico, utilizou-se a pesquisa documental e os dados financeiros do Sistema de Informações sobre Orçamentos Públicos em Educação (SIOPE) e do Portal do FNDE. As conclusões indicam que os recursos oriundos do PAR representam em média 2,5\% das despesas com a função educação. Nesse aspecto, o regime de colaboração propagado se coaduna com a lógica que considera demandarem apenas planejamento e gestão os problemas relativos à qualidade da educação, mantendo-se as assimetrias na capacidade de provimento das políticas educacionais.
\end{abstract}

Palavras-chave: Financiamento da educação; Plano de Ações Articuladas; regime de colaboração; relações federativas.

\begin{abstract}
The paper deals with education funding through the PAR - Articulated Actions Plan in the municipalities of Altamira, Barcarena, Belém, Cametá and Castanhal, from 2010 to 2014, intending to measure the responsibilities of federal entities on the implementation of the collaboration regime. File research and financial data from SIOPE - Information System on Public Budget on Education and the FNDE website were used as methodological procedure. It was concluded that resources from PAR represent an average of 2,5\% of the expenses on education. In this aspect, the spread collaboration regime matches with the thinking that quality education issues demand only planning and management, maintaining asymmetries on the supplying power of the educational policies.
\end{abstract}

Keywords: Education funding; Articulated Actions Plan; collaboration regime; federative relations.

Resumen: El artículo trata del financiamiento de la educación en el contexto del Plan de Acciones Articuladas - PAR en las ciudades de Altamira, Barcarena, Belém, Cametá y Castanhal, de 2010 a 2014, con la perpectiva de dimensionar 
la responsabilidad de las entidades federales en la efetivación del régimen de colaboración. Como procedimiento metodológico, se utilizó la investigación documental y los datos financieros del Sistema de Información sobre los presupuestos públicos en la Educación - SIOPE y del Portal de FNDE. Las conclusiones indican que los recursos oriundos del PAR representan un promedio de 2,5\% del gasto en función de la educación. En este sentido, el regimen de colaboración propagado es coherente con la lógica que considera que los problemas relacionados con la calidad de la educación sólo requieren una planificación y gestión, manteniendo las asimetrías en la capacidad de provimiento de las políticas educativas.

Palabras clave: Financiamiento de la educación; Plan de Acciones Articuladas; régimen de colaboración; relaciones federativas.

\section{INTRODUÇÃO}

Historicamente, as relações intergovernamentais, em matéria de educação têm sido objeto de estudos interessantes, nos quais são questionadas as formas de descentralização ou de repasse de responsabilidades aos municípios no provimento da educação. Um dos paradoxos mais instigantes da temática reside no fato de o ente federado detentor da maior parcela do fundo público ser o que menos gasta com educação e o menos capacitado financeiramente ser o que vem assumido crescentemente as maiores responsabilidades na garantia desse direito à população. Diante disso, questiona-se, num cenário marcado por acentuadas desigualdades orçamentárias, como assegurar o acesso de crianças e jovens ainda fora dos sistemas de ensino a um ensino de qualidade e profissionais da educação valorizados sem os recursos suficientes? As perspectivas apontam para ações de colaboração de forma articulada. Mas, quais as bases e formas sobre as quais se assentam as relações intergovernamentais entre os entes federados para garantir que esses princípios constitucionais sejam efetivados?

O texto faz uma discussão sobre essas relações a partir do Plano de Ações Articuladas, focalizando as experiências vivenciadas em cinco municípios do estado do Pará: Altamira, Barcarena, Belém, Castanhal e Cametá, de 2010 a 2014, na perspectiva de dimensionar a responsabilidade da União, do estado e dos municípios na efetivação do regime de colaboração, no tocante à qualidade da educação.

Para isso, são abordadas questões referentes à política de financiamento da educação a partir da segunda metade dos anos 1990, enfatizando-se as relações intergovernamentais entre a União e os municípios com a implementação da política de fundos (FUNDEF e FUNDEB). A seguir, as relações intergovernamentais são analisadas à luz do Plano de Ações Articuladas (PAR) e, por fim, aprofundam-se as discussões a partir das experiências vivenciadas pelos municípios.

152 - RBPAE - v. 32, n. 1, p. 151 - 169 jan./abr. 2016 


\title{
A POLÍTICA DE FINANCIAMENTO DA EDUCAÇÃO NO BRASIL, AS RELAÇÕES FEDERATIVAS E O PLANO DE AÇÕES ARTICULADAS (PAR)
}

\author{
A política de financiamento da educação no Brasil no contexto das relações \\ federativas
}

A relação que a União vem estabelecendo com os municípios sustenta-se no preceito constitucional que os elevou ao status de ente federativo com o mesmo grau de autonomia que a União, os estados e o Distrito Federal. Autonomia que se expressa no poder de: tributar, para que possa prestar serviços aos cidadãos; governar, o que é assegurado por meio de eleição para escolha de prefeito; normatizar, por meio da Câmara de vereadores; organizar-se, por meio da Lei Orgânica Municipal. Desse modo, o município constitui-se como ente dotado de poder estatal e de autonomia política, administrativa e financeira (Constituição Federal de 1988, art. 18 e 30).

Parte-se do entendimento de que o federalismo consiste em "uma forma de organização territorial do Estado e, como tal, tem enorme impacto na organização dos governos e na maneira como eles respondem aos cidadãos" (ABRUCIO, 2010, p.39). Nesse sistema, os entes federados gozam de autonomia e compartilham legitimidade no processo decisório sobre as políticas públicas. Por essa razão, é possível a mais de um agente governamental atuar numa mesma direção no atendimento aos cidadãos, sendo, em alguns casos, pertinente "ação conjunta e/ou a negociação entre os níveis de governo em questões condicionadas à interdependência entre eles" (Idem, p. 39).

O financiamento da educação é um caso emblemático, pois os entes federados atuam na mesma direção, embora com responsabilidades e capacidades de financiamento diferenciadas (Inciso IX do art. 24 da Constituição Federal de 1988). Quanto a isso, Oliveira (2010) pertinentemente alerta para o fato de que, na estrutura do federalismo nos moldes brasileiros, há "uma diferenciação acentuada na distribuição das receitas fiscais, no padrão das políticas públicas e, no caso da educação, grande diversidade na forma e nos meios de provimento desse direito" (p. 9). Essa situação decorre do desenvolvimento desigual dos estados e municípios e do desempenho da União em não garantir a redução das assimetrias por meio da transferência de recursos compatíveis com as necessidades locais.

Affonso (1995) ajuda a situar a discussão sobre federalismo e financiamento da educação ao esclarecer que "a federação é uma forma de organização territorial do poder, fundada na articulação do Poder central com os poderes regional e local e materializada em um conjunto complexo de alianças 
por meio dos fundos públicos” (p. 39). Esse autor também adverte para um complicador nas relações entre os entes federados ou intergovernamentais que são as desigualdades econômicas produtoras de assimetrias em várias direções e dimensões, dificultando o desenvolvimento de relações de poder equilibradas, necessárias para a manutenção do sistema. Affonso sustenta que a contribuição para assegurar o equilíbrio deveria vir do ente federado responsável pela manutenção das relações e que dispõe de receitas específicas para desempenhar tal função - a União - por meio dos fundos públicos. Os fundos públicos desempenham papel crucial em países com acentuadas desigualdades, exigindo, "uma transferência significativa de recursos públicos entre as regiões com desigual capacidade econômica e grandes assimetrias sociais. O mercado mostra-se incapaz de soldar per se a aliança federativa" (Idem, p.58).

Nesse contexto, a União como responsável por manter o equilíbrio na diversidade deverá coordenar políticas que garantam o direito de todos à educação de forma compartilhada com os membros da federação, pautada em princípios, dentre os quais "garantia de padrão mínimo de qualidade" e "valorização dos profissionais da educação escolar; garantidos, na forma da lei, planos de carreira, com ingresso exclusivamente por concurso público de prova e títulos, aos da rede pública" (Inciso V com redação dada pela EC. n 53, de 19.12.2006); e do piso salarial profissional nacional para os profissionais da educação escolar pública, nos termos de lei federal (Inciso VIII acrescentado pela EC. nº. 53, de 19.12.2006).

Entendemos ser o financiamento da educação o elemento fulcral do regime de colaboração entre os entes federativos, visto que a ausência de recursos financeiros tende a dificultar e até impossibilitar a materialização da tão almejada qualidade do ensino. Estudos têm mostrado que o atual sistema tributário é concentrador de recursos na União, sendo os municípios os entes menos aquinhoados, pois a União vem sistematicamente concentrando mais da metade da receita fiscal disponível (REZENDE, 2010). As principais fontes de financiamento da educação são as receitas de impostos e o salário educação, que "representam em termos de volume de recursos e de regularidade a receita que tem financiado a expansão e a qualificação da educação escolar pública no país" (FARENZENA, 2006, p. 82). No âmbito do financiamento da educação, a União instituiu, em 1996, a Política de Fundos, inicialmente por meio do Fundo de manutenção e desenvolvimento do ensino fundamental e valorização do magistério (FUNDEF), posteriormente substituído pelo Fundo de Manutenção e Desenvolvimento da Educação Básica e Valorização dos Profissionais da educação (FUNDEB) (2007), com objetivo, dentre outros, de ampliar o acesso, assegurar a qualidade do ensino e valorizar os profissionais da educação. Ainda que possam ser concebidas como de coordenação da política nacional e garantam o fluxo de 
recursos, importante no âmbito estadual, essas medidas ainda deixam muito a desejar no combate às desigualdades educacionais e à garantia da qualidade do ensino e valorização dos profissionais do magistério.

O FUNDEF foi criado pela Emenda Constitucional nº14/1996 para vigorar por dez anos. Era constituído por 15\% dos principais recursos vinculados à educação (FPE, FPM, ICMS, IPI-Exp.) e pela compensação financeira decorrente da Lei Kandir/96. Redistribuía os recursos, no âmbito dos Estados, de acordo com o número de alunos matriculados no Ensino Fundamental. A participação da União ocorria apenas naqueles estados em que o valor mínimo por aluno não fosse alcançado ${ }^{1}$.

Muito embora o argumento justificador da institucionalização do FUNDEF tenha sido o de universalizar o atendimento do Ensino Fundamental e de valorizar o magistério, a intenção da União foi promover a municipalização das matrículas, adotando o recurso financeiro como estratégia para atrair adesão dos municípios, haja vista que a autonomia política passa também pela não intervenção e pelo respeito nas relações intergovernamentais. A carência de recursos financeiros e as possibilidades de aumentar as receitas municipais foram as principais motivações para se vivenciar um processo acelerado de municipalização das matrículas. No caso do Estado do Pará, em curto período de tempo, alterouse o padrão de atendimento da Educação Básica de estadualizado para o de municipalizado, assim como em nível nacional. Em decorrência, houve redução das matrículas da Educação Infantil e aumento do acesso ao Ensino Médio, mas em proporções inferiores ao repasse das matrículas para as redes municipais (GEMAQUE, 2004; GUTIERRES, 2010). Ao término do FUNDEF, o cenário permaneceu praticamente o mesmo: o atendimento do Ensino Fundamental não foi universalizado; os professores não foram valorizados e a qualidade do ensino ficou ainda mais comprometida. As possibilidades restringiram-se aos limites orçamentários dos estados e municípios. Os desafios e responsabilidades dos municípios foram ampliados visto que o maior déficit de atendimento escolar é na Educação Infantil - etapa de ensino que demanda maiores aportes de recursos financeiros. Além disso, os municípios assumiram o compromisso de valorizar o magistério, por meio de aprovação de Planos de Carreira e Remuneração (PCCR) e de assegurar remunerações condignas.

Em substituição ao FUNDEF, foi aprovado o FUNDEB, por meio da Emenda Constitucional no 53 de 20 de dezembro de 2006 e regulamentado pela

1 O Fundef era constituído por $15 \%$ de alguns recursos vinculados à educação (Fundo de Participação dos Estados (FPE); Fundo de Participação dos Municípios (FPM); Impostos sobre a Circulação de Mercadorias e Serviços (ICMS); Imposto sobre os Produtos Industrializados para fins de Exportação (IPI-Exp.); Compensação Financeira decorrente da desoneração das exportações). Os Estados que receberam complementação da União foram: Pará, Maranhão, Piauí, Bahia. 
Lei 11.494 de 20 de junho de 2007. As principais modificações consistiram na ampliação: da vigência do Fundo para toda educação básica; dos percentuais de vinculação de recursos, de 15 para 20\%; no volume de recursos; na participação da União para o equivalente a 10\% do total do Fundo; dentre outras. Com isso, aumentou-se o fluxo de recursos, sobretudo dos governos estaduais para os municipais e também da União. Por outro lado, tem-se também a ampliação do quantitativo de alunos contemplado pelo Fundo e mais um conjunto de outras medidas do governo federal, cujo apoio financeiro foi acoplado aos recursos do FUNDEB. Dentre eles, destacam-se o Piso Salarial Profissional Nacional e programas direcionados para melhoria da qualidade do ensino. Do total de recursos de complementação da União aos fundos estaduais é deduzido 10\% para essa finalidade (Art. $7^{\circ}$ da Lei 11.494/07). Dessa feita, a complementação da União ao Fundo deverá ter efeito multiplicador ao contemplar uma multiplicidade de programas instituídos com a intenção de melhorar a qualidade do ensino. Essa complementação, acrescida dos recursos da quota-parte federal do salário educação e de outras fontes do FNDE, vai constituir as bases do apoio financeiro da União e do regime de colaboração.

Nesse processo, a colaboração entre os entes federados e, particularmente, da União para com os municípios tem-se se pautado por repasses de recursos descolados das reais necessidades locais, por meio de incentivos financeiros indutores de políticas cuja maior parte das despesas (contrapartida) são custeadas com recursos dos próprios municípios (BREMAEKER, 2003). Algumas são efetivadas apenas parcialmente ou de forma inadequada. Essa situação é desfocada pela veiculação de notícias de desvios de recursos da educação, apropriação indevida e incompetência administrativa e técnica dos municípios. Não negamos a veracidade das denúncias, mas elas não se constituem no problema central da falta de qualidade na educação brasileira nem são responsáveis pela não valorização do magistério.

Os dados apresentados por Castro (2014) são bem ilustrativos das responsabilidades crescentes assumidas pelos municípios que se expressam também nas despesas da educação, tal como nas áreas da saúde e da assistência.

Tabela 1: Gastos Públicos com Educação (\%), Por Unidade da Federação 1995-2010

\begin{tabular}{|l|c|c|c|c|c|}
\hline \multicolumn{2}{|c|}{ Governo Federal } & \multicolumn{2}{c|}{ Governos Estaduais } & \multicolumn{2}{c|}{ Governos Municipais } \\
\hline 1995 & 2010 & 1995 & 2010 & 1995 & 2010 \\
\hline 23,8 & 19,7 & 48,3 & 41,2 & 27,9 & 39,1 \\
\hline
\end{tabular}

Fonte: (CASTRO, 2014) 
Os dados evidenciam claramente o grau de descentralização da execução dos gastos na área de educação por nível de governo. Desse modo, o ente federado detentor de maior parte do fundo público, constituído pelos tributos - a União - no decorrer de 15 anos reduziu sua participação nos gastos com educação, assim como os governos estaduais, em detrimento do ente menos aquinhoado, o município, que ampliou sua participação na execução dos gastos, de 27,9 para $39,1 \%$.

Diante disso, questiona-se novamente: como assegurar educação de qualidade e profissionais valorizados num contexto de acentuadas desigualdades sem garantir uma política responsável de desconcentração de renda? O PAR se apresenta como essa possibilidade?

\section{O PLANO DE AÇÕES ARTICULADAS - COMPROMISSO TODOS PELA EDUCAÇÃO}

A análise do PAR à luz do financiamento da educação remete às referências teóricas sobre relações intergovernamentais (RIGs) e descentralização, concebidas como conceitos associados às teorizações sobre os sistemas federativos, mas que não se constituem em arranjos exclusivos dessa forma de organização territorial. Sobre isso, Souza (2008) esclarece que os sistemas federativos são mais amplos que as relações intergovernamentais e que os processos de descentralização. A diferenciação reside na amplitude, visto que os primeiros envolvem o governo e os poderes legislativos e judiciários, os sistemas partidários, eleitorais, a política econômica, enquanto "os processos intergovernamentais combinam tão-somente Executivos de vários níveis e são menos sujeitos a produzirem efeitos legais e jurídicos" (p. 36-37).

Diante disso, Souza (2008) argumenta:

Os conceitos de RIGs e de descentralização são muitas vezes mais apropriados do que o de federalismo para analisar as relações que se estabelecem entre níveis de governo, quando da implementação de políticas, e para responder às questões sobre o que os governos fazem e como fazem (p. 37).

As relações intergovernamentais, segundo Souza (2008), são reconhecidas academicamente como área de estudos, apesar de serem ainda pouco utilizadas no Brasil como referência teórica. Em geral são categorizadas em dois grupos: "relações verticais (entre instâncias de diferentes níveis de governo) e horizontais (entre instâncias do mesmo nível, inclusive entre Estados soberanos)" (p. 37-38). Um fator importante nessa abordagem para a área da educação é que os estudos sobre as RIGs se voltam para desvelar o desenvolvimento de programas que 
envolvem várias estruturas decisórias e arranjos multiorganizacionais, combinando estruturas e processos em interação na prática. As instâncias envolvidas nesse processo, por sua vez, desenvolvem trocas mútuas, podendo criar também novas estruturas e processos, os quais são ensejados pelas políticas públicas. Nessa perspectiva, os conflitos entre os níveis de governo não representam disputas, mas possibilidades "de articulação entre essas esferas e da convivência entre estruturas (esferas governamentais) e processos (formulação e implementação de políticas públicas)" (Idem, p.38).

$\mathrm{Na}$ visão do autor, a incorporação dessa abordagem é promissora em países como o Brasil "que desenvolveram complexos sistemas de relações intergovernamentais para implementar políticas sociais" (Ibidem).

No que concerne à descentralização como referência teórica, a autora defende que o primeiro passo a ser tomado é conceituá-la. Desse modo, "descentralizar é dispersar ou distribuir poder que estava anteriormente concentrado no centro" (Ibidem). Embora a descentralização possa ter vários formatos (funcional, territorial, econômica, tributária, política) desponta como uma questão política que representa a transferência de autoridade no processo de tomada de decisão. A descentralização fiscal - variável importante quando se trata de níveis de governo - representa "o aumento dos recursos e da capacidade decisória sobre sua aplicação" e a descentralização administrativa significa "o deslocamento do eixo de responsabilidade pela elaboração e/ou implementação de políticas, sejam elas financiadas ou não por outras esferas" (Idem, p.39).

Com base nessas informações teóricas, questionamos: (1) o PAR tem possibilitado o desenvolvimento de trocas mútuas nas relações intergovernamentais, novas estruturas e processos ensejados pelas políticas públicas? (2) O PAR permite a transferência de autoridade no processo de tomada de decisão? (3) O PAR tem assegurado o aumento dos recursos e da capacidade decisória sobre sua aplicação? Todas essas questões são importantes, mas, neste artigo, limitamonos a verificar o quantitativo de recursos financeiros novos após a adesão ao PAR em cinco municípios paraenses e inferir algumas sinalizações sobre o regime de colaboração. Antes, porém, é importante destacar algumas características do Plano de Metas Compromisso Todos pela Educação e do PAR.

O PDE e o Plano de Metas Compromisso Todos pela Educação (PMCTE) se apresentaram como um grande guarda-chuva, que integrou ações pré-existentes no Ministério da Educação e, ainda, outras ações novas ou remodeladas, com foco na Educação Básica, Superior, Profissional, alfabetização e diversidade.

O Decreto $\mathrm{n}^{\circ} 6.094$ de 24 de abril de 2007 expressa mais uma das investidas da União de descentralizar ou desconcentrar a execução dos gastos com educação sem descentralizar o poder de decisão, ao instituir o Plano de 
Metas, que visa a estabelecer o compromisso de melhorar a qualidade da educação por meio da conjugação de esforços do Estado e da sociedade, representados pela União, estados, Distrito Federal, municípios, família e comunidade. Essa iniciativa é bastante reveladora de um tipo de relação intergovernamental assimétrica que desconsidera as desigualdades econômicas, as diversidades culturais e a importância da participação na tomada de decisão dos sujeitos que executarão as ações (CAMINI, 2010).

Desse modo, o referido Decreto

Dispõe sobre a implementação do Plano de Metas Compromisso Todos pela Educação, pela União Federal, em regime de colaboração com Municípios, Distrito Federal e Estados, e a participação das famílias e da comunidade, mediante programas e ações de assistência técnica e financeira, visando a mobilização social pela melhoria da qualidade da educação básica (BRASIL, 2007).

Conforme anunciado no preâmbulo, trata-se de um plano estabelecido pela União, mas para ser executado em regime de colaboração com os demais entes do poder público e com participação da sociedade civil, representada pela família e pela comunidade. A participação da União, além das decisões iniciais dar-se-á de forma direta, quando couber, e por meio de incentivos e apoio à implementação pelos Municípios, Estados e Distrito Federal.

O referido Plano de Metas estabelece 28 diretrizes reveladoras de seus pressupostos fundantes, a partir dos quais a União interpreta as origens ou as razões pelas quais o país não consegue galgar índices ou resultados educacionais de qualidade. Esses pressupostos, por sua vez, nortearão o tipo e formas de apoios técnicos e financeiros revelados nas várias medidas reguladoras, por meio de leis, resoluções e manuais. A análise das 28 diretrizes presentes no Decreto no 6.094 de 24/04/2007 permite abstrair pelos menos três pressupostos: (1) melhorar a qualidade da educação é uma questão de gestão, demandando articulação de esforços e compromissos entre poder público e sociedade. Portanto, os recursos disponibilizados são suficientes. O problema central reside na incompetência de gestão dos recursos; (2) o Poder Público para cumprir as metas precisará da ajuda da iniciativa privada; (3) a construção da qualidade da educação depende de questões intrínsecas à escola ou aos sistemas de ensino. Neste aspecto, os profissionais da educação são os principais responsáveis.

Com base nesses pressupostos, o Plano de Metas propõe, dentre outras ações: focar na aprendizagem; acompanhar o processo educacional; ampliar o tempo de permanência na escola; reduzir o tempo de deslocamento do aluno até a escola; ampliar a formação ética, artística e física; assegurar formação continuada aos professores; criar PCCRs; buscar parcerias externas à escola; valorizar o 
mérito, formação e desempenho dos professores; estabelecer regras claras para nomeação e exoneração de diretores; ampliar a participação e controle social na gestão da escola e no provimento de recursos financeiros.

Dentre as proposições, nenhuma enfatiza a ampliação de recursos financeiros para a educação, tendo em vista que a falta de qualidade é vista como uma questão de gestão, formação e compromisso. Por certo, a construção da qualidade de ensino e a valorização dos professores passa por essas dimensões, mas educação de qualidade tem um custo que não é pequeno, tal como evidenciado em países membros da Organização para a Cooperação e Desenvolvimento Econômico (OCDE) (PINTO, 2015; AMARAL, 2015).

Como, no processo de municipalização das matrículas, a articulação em torno do compromisso de todos pela Educação se dá por meio da adesão - concordância dos partícipes - tendo em vista o princípio da autonomia, que implicou na assunção da responsabilidade por promover a qualidade da educação em seu espaço territorial. Conforme informa Camini (2010) ainda em 2007, 100\% dos municípios e Estados haviam assinado o documento de adesão. Quem ousaria não assinar um termo com intenções tão nobres? Quem ousaria não assinar o termo diante de tamanhos desafios assumidos e da escassez de receitas para a educação? Importa destacar que o apoio técnico ou financeiro da União foi condicionado à assinatura do termo.

Inicialmente, as condicionalidades do apoio técnico ou financeiro da União exigidas dos colaboradores/implementadores foram: cumprimentos das metas referenciadas na evolução do IDEB, observados os limites orçamentários e operacionais da União; priorização do ente que mostra empenho e condições objetivas para melhorar os índices do IDEB e no atendimento às exigências normativas do FNDE; elaboração de um Plano de Ação Articulado (arts. $5^{\circ}$ e $8^{a}$ do Decreto no 6.094 de 24/04/2007).

De acordo com o Decreto $n^{\circ} 6.094$ de 24/04/2007, o PAR consiste em um "conjunto articulado de ações, apoiado técnica ou financeiramente pelo Ministério da Educação, que visa ao cumprimento das metas do Compromisso e a observância das suas diretrizes em um Plano elaborado pelos municípios, Estados e Distrito Federal" (Art. 90 do Decreto no 6.094 de 24/04/2007). O apoio técnico ou financeiro foi regulamentado pela Resolução CD/FNDE $n^{\circ}$ 029, de 20 de junho de 2007 que "estabelece os critérios, os parâmetros e os procedimentos para a operacionalização da assistência financeira suplementar a projetos educacionais, no âmbito do Compromisso Todos pela Educação, no exercício de 2007” (BRASIL, 2007).

A Lei $n^{\circ}$ 12.695/2012 define as quatro dimensões abrangidas pelo PAR passiveis de serem financiadas ou receberem apoio técnico do MEC, sendo elas: 
Art. 2o - O PAR será elaborado pelos entes federados e pactuado com o Ministério da Educação, a partir das ações, programas e atividades definidas pelo Comitê Estratégico do PAR, de que trata o art. 3o. [...] \10 A elaboração do PAR será precedida de um diagnóstico da situação educacional, estruturado em 4 (quatro) dimensões: [...]I - gestão educacional; [...]II - formação de profissionais de educação; [...]III - práticas pedagógicas e avaliação; [...] IV -infraestrutura física e recursos pedagógicos (BRASIL, 2012).

Esses eixos ou dimensões são subdivididos por áreas e indicadores ${ }^{2}$, que, para efeito de diagnóstico, monitoramento e avaliação, recebem pontuações de acordo com a situação apresentada pelo sistema educacional, representadas em quatro níveis (1, 2, 3 e 4). Dependendo da pontuação, o sistema gera ações que poderão ser financiadas pelos municípios ou contar com o apoio técnico ou financeiro da União. A Lei n 12.695 de 25 de junho introduziu medidas importantes relacionadas ao apoio técnico ou financeiro da União por meio do PAR. Dentre as medidas estabelecidas por essa lei, destacam-se: a) inclusão dos polos presenciais do sistema Universidade Aberta do Brasil na assistência financeira do Programa Dinheiro Direto na Escola; b) contemplação das instituições comunitárias que atuam na educação do campo com recursos do FUNDEB; c) definição da assistência financeira da União para Atendimento à Educação de Jovens e Adultos, no âmbito do Programa de Apoio aos Sistemas de Ensino; c) a transferência de recursos da União aos Estados, ao Distrito Federal e aos Municípios, por meio do FNDE, como apoio financeiro à execução das ações do PAR, sem a necessidade de convênio, ajuste, acordo ou contrato; d) autorização ao FNDE para suspender as parcelas de recursos previstas aos entes federados, caso não haja cumprimento das metas. O Art. 1o dessa mesma lei determina que "O apoio técnico ou financeiro prestado em caráter suplementar e voluntário pela União às redes públicas de Educação Básica dos estados, do Distrito Federal e dos municípios será feito mediante a pactuação de Plano de Ações Articuladas (PAR)" (BRASIL, 2012). De acordo com o Art. $4^{\circ}$ da Lei 12.695 de 2012, os repasses serão feitos sem necessidade de convênio:

Art. 4o A União, por meio do Ministério da Educação, fica autorizada a transferir recursos aos estados, ao Distrito Federal e aos municípios, com a finalidade de prestar apoio financeiro à execução das ações do PAR, sem a necessidade de convênio, ajuste, acordo ou contrato (Idem).

Vejamos como isso impacta no financiamento da educação em cinco municípios do Pará. 2 A primeira versão do PAR contou com quatro dimensões, 15 áreas e 52 indicadores; a segunda
contou com quatro dimensões, 17 áreas e 82 indicadores. 


\section{O FINANCIAMENTO DA EDUCAÇÃO NOS MUNICÍPIOS DE ALTAMIRA, BELÉM, BARCARENA, CAMETÁ E CASTANHAL: REGIME DE COLABORAÇÃO?}

Os cinco municípios do estado do Pará foco do estudo são: Altamira, Barcarena, Belém, Cametá, Castanhal, que apresentam extensão territorial, população e situação econômica variada, conforme a Tabela 2:

Tabela 2: Municípios por Extensão Territorial, População, PIB e PIB per capita

\begin{tabular}{|c|c|c|c|c|}
\hline Municípios & $\begin{array}{c}\text { Extensão territorial } \\
\left(\mathbf{K m}^{2}\right)\end{array}$ & $\begin{array}{c}\text { População } \\
(\mathbf{2 0 1 0})\end{array}$ & $\begin{array}{c}\text { PIB (valor em Mil, } \\
\mathbf{2 0 1 1})\end{array}$ & $\begin{array}{c}\text { PIB per capita (R\$ } \\
\mathbf{1 , 0 0 , 2 0 1 1 )}\end{array}$ \\
\hline Altamira & $159.533,255$ & 105.106 & 890.626 & 8.841 \\
\hline Barcarena & $1.310,588$ & 99.800 & 3.659 .053 & 35.640 \\
\hline Belém & $1.059,458$ & 1.392 .031 & 19.666 .725 & 14.027 \\
\hline Cametá & $3.081,367$ & 120.904 & 412.715 & 3.364 \\
\hline Castanhal & $1.028,889$ & 173.096 & 1.618 .187 & 9.188 \\
\hline
\end{tabular}

Fonte: Pará/IDESP/SEPOF (2014).

A capital do Estado, Belém, apresenta o maior contingente de habitantes (1.392.003) entre os cinco municípios pesquisados, o que, certamente, aumenta a demanda por educação. O município de Altamira possui a maior extensão territorial do estado e do país, com quase $160.000 \mathrm{Km}^{2}$, o que certamente tende a aumentar as despesas com o transporte escolar dos estudantes. O município de Barcarena destaca-se como o de mais alto PIB per capita dentre os cinco, visto que, no ano de 2011, era o terceiro colocado em âmbito estadual nesse quesito (PARÁ, 2014).

A maioria dos municípios (Altamira, Belém e Cametá) assinou o termo de Adesão ao PAR no ano de 2008, conforme consta dos Relatórios Públicos do MEC/SIMEC referentes aos municípios, discriminados na tabela 3, a seguir: 


\section{Tabela 3: Número e ano do Termo de Adesão ao PAR e gestores municipais}

\begin{tabular}{|c|c|c|}
\hline Municípios & No Termo de Adesão $^{\text {Gestor do Período em análise }}$ \\
\hline Altamira & $\mathrm{N}^{0} 15.023 / 2008$ & Odileida Maria de Souza Sampaio (PSDB) \\
\hline Barcarena & $\mathrm{N}^{0} 26.836 / 2011$ & João Carlos dos Santos Dias (PMN) \\
\hline Belém & $\mathrm{N}^{0} 16.681 / 2008$ & Duciomar Gomes da Costa (PTB) \\
\hline Cametá & $\mathrm{N}^{0} 19.921 / 2008$ & José Waldoli Filgueira Valente (DEM) \\
\hline Castanhal & $\mathrm{N}^{0} 22.853 / 2009$ & Hélio Leite da Silva (PR) \\
\hline
\end{tabular}

Fonte: Altamira, Belém e Cametá 2008; Castanhal, 2009; Barcarena, 2011.

\section{FINANCIAMENTO DA EDUCAÇÃO NOS MUNICÍPIOS}

Cabe aos municípios a responsabilidade constitucional de atendimento à Educação Infantil e ao Ensino Fundamental (EC/14) - etapa da Educação Básica que concentra a maior parcela de crianças e jovens em idade escolar. E o PAR tem como pressuposto o regime de colaboração nessa tarefa, na perspectiva de qualificar a educação. Mas, em que medida isso vem se concretizando nos municípios da pesquisa quando se trata do repasse de novos recursos para a educação? Nesse item identificamos os recursos financeiros destinados à educação nos municípios da pesquisa, referentes ao período de 2010 a 2014³ , por fonte, para tentar avaliar a dinâmica dos recursos e identificar os valores da contribuição da União aos municípios, em decorrência do PAR.

Os recursos financeiros da União para os municípios em decorrência do PAR, considerados novos no período, foram os relativos ao Proinfância, Educação Inclusiva, transporte escolar (Caminho da Escola), construção de quadras esportivas nas escolas, alfabetização de adultos, Pró-jovem e PROINFO. A tabela 4 apresenta os valores repassados aos municípios por Programa, de 2010 a 2014.

Tabela 4: Altamira, Barcarena, Belém, Castanhal e Cametá: Programas de Assistência Financeira da União decorrentes do PAR, de 2010-2014

\begin{tabular}{|c|c|c|c|c|c|}
\hline Programa & Altamira & Barcarena & Belém & Cametá & Castanhal \\
\hline Proinfância Constr. de Creche & 1.320 .634 & 7.756 .360 & 1.684 .667 & 1.600 .733 & 4.824 .276 \\
\hline Proinfância Equipam./Mobiliário & 1.570 .318 & 763.179 & - & 193.065 & 1.446 .903 \\
\hline Const. de Quadras & 1.214 .005 & 2.548 .152 & 1.748 .934 & 752.242 & - \\
\hline
\end{tabular}

3 Esse período foi escolhido porque embora os municípios tenham aderido ao PAR a partir de 2008, na maioria deles, somente a partir de 2010 começam a receber recursos de programas novos associados ao PAR. 
Tabela 4: Altamira, Barcarena, Belém, Castanhal e Cametá: Programas de Assistência Financeira da União decorrentes do PAR, de 2010-2014

\begin{tabular}{|c|c|c|c|c|c|}
\hline Programa & Altamira & Barcarena & Belém & Cametá & Castanhal \\
\hline Educação Inclusiva & - & - & 236.986 & & - \\
\hline $\begin{array}{c}\text { Infraestrtura do Ensino. } \\
\text { Fundamental }\end{array}$ & - & - & & 371.250 & - \\
\hline Apoio/manutenção da.creche & 212.215 & 738.023 & 4.103 .648 & 212.215 & 6.499 \\
\hline Caminho da Escola & 713.000 & - & 1.001 .650 & 1.602 .463 & 1.196 .560 \\
\hline PAR/Transf. Direta & - & - & 999.934 & - & - \\
\hline PROINFO & 60.225 & - & - & - & 71.175 \\
\hline Brasil Alfabetizado & 172.667 & - & 678.165 & 46.650 & - \\
\hline Pró-Jovem & - & - & 19.290 .682 & 1.116 .418 & 297.500 \\
\hline Total & $\mathbf{5 . 2 6 3 . 0 6 4}$ & 11.805 .714 & 29.744 .666 & $\mathbf{5 . 8 9 5 . 0 3 6}$ & $\mathbf{7 . 9 4 2 . 9 1 3}$ \\
\hline
\end{tabular}

Fonte: SIOPE/FNDE.

Todos os municípios pesquisados foram contemplados com recursos do Proinfância para construção de creches. O mesmo programa destinou recursos para aquisição de equipamentos e mobiliários para a Educação Infantil em todos os municípios, exceto para Belém. A capital do estado destacou-se por ter recebido os maiores valores relativos à manutenção de creches e ao programa Pró-Jovem, enquanto Barcarena e Castanhal obtiveram maiores valores para a construção de creches. Exceto Barcarena, todos receberam recursos oriundos do Programa Caminho da Escola, para aquisição de ônibus ou barco escolar, no período pesquisado.

Além dos recursos do FUNDEB e dos novos recursos do PAR, verificamos também os recursos do salário educação, das transferências de Programas do FNDE - Programa Nacional de Alimentação Escolar (PNAE); Programa de Apoio ao Transporte Escolar (PNATE); Programa Dinheiro Direto na Escola (PDDE ${ }^{4}$ ) no mesmo período, 2010 a $2014^{5}$. Em seguida, levantamos as despesas da Função Educação ${ }^{6}$ para dimensionar o percentual de cada fonte em relação a essas despesas. Os totais de cada programa e fonte e seus percentuais em relação ao que foi gasto na Função Educação no período estão na tabela a seguir:

\footnotetext{
4 Trata-se dos recursos do PDDE referentes às escolas que não possuem Unidades Executoras. Não incluem, portanto, os recursos repassados diretamente para a escola via PDDE e os associados ao PDE/Escola.

5 Os valores foram extraídos do site do SIOPE por Programa ano a ano e em seguida somados.

6 As Despesas da Função Educação congregam gastos de receitas oriundas de todas as fontes arrecadadas pelo município ou estado. Os totais de cada ano foram somados de 2010 a 2011 para permitir a comparação com o total dos demais.
}

164 - RBPAE - v. 32, n. 1, p. 151 - 169 jan./abr. 2016 
Tabela 5: Participação percentual das receitas dos Programas do PAR nas Despesas da Função Educação dos municípios de 2010 a 2014

\begin{tabular}{|c|c|c|c|c|c|c|c|}
\hline \multirow[b]{2}{*}{ Município } & \multicolumn{5}{|c|}{ RECEITAS POR PROGRAMAS/FONTES } & \multirow{2}{*}{$\begin{array}{l}\text { Programas } \\
\text { decorrentes } \\
\text { do PAR }\end{array}$} & \multirow{2}{*}{$\begin{array}{c}\text { Despesa da } \\
\text { Função } \\
\text { Educação }\end{array}$} \\
\hline & PNAE & PNATE & PDDE & $\begin{array}{c}\text { Salário } \\
\text { Educação }\end{array}$ & FUNDEB & & \\
\hline Altamira & 10.485 .038 & 1.407 .823 & 151.368 & 7.238 .741 & 199.317.049* & 5.263 .065 & $266.515 .520^{*}$ \\
\hline$\%$ & 3,9 & 0,5 & 0,0 & 2,7 & 74,7 & 1,9 & 100 \\
\hline Barcarena & 12.367 .793 & 3.262 .484 & 227.774 & 6.871 .434 & 238.729 .643 & 11.805 .715 & 370.851 .136 \\
\hline$\%$ & 3,3 & 0,8 & 0,0 & 1,8 & 64,3 & 3,1 & 100 \\
\hline Belém & 31.956 .644 & 353.058 & 12.772 & 20.942 .263 & 716.211 .622 & 29.744 .668 & 1.882.782.347 \\
\hline$\%$ & 1,6 & 0,0 & 0,0 & 1,1 & 38,0 & 1,5 & 100 \\
\hline Cametá & 18.619 .520 & 11.380 .141 & 416.585 & 11.234 .291 & $245.909 .980^{*}$ & 5.895 .037 & $286.864 .432^{*}$ \\
\hline$\%$ & 6,4 & 3,9 & 0,1 & 3,9 & 85,7 & 2,0 & 100 \\
\hline Castanhal & 17.995 .122 & 1.798 .968 & 90.385 & 7.725 .420 & 258.006 .974 & 7.942 .815 & 368.445 .878 \\
\hline$\%$ & 4,8 & 0,4 & 0,0 & 2,0 & 70,0 & 2,1 & \\
\hline
\end{tabular}

Fonte: SIOPE/FNDE (2014). Nota 1. Valores nominais. Nota 2*: Os valores do FUNDEB e da Função Educação de Altamira e Cametá não incluem os anos de 2011 e de 2011 e 2012 respectivamente, pela ausência na base SIOPE.

Os dados da tabela 5 nos permitem dimensionar o valor relativo das várias fontes de receita na composição das despesas com educação em cada município, considerando-se os anos de 2010 a 2014. Verifica-se que o FUNDEB representa a maior parte dos recursos que financiam a educação nos municípios, exceto em Belém onde essa fonte representou apenas 38\% do que foi despendido no período. Pela sua condição de capital do Estado, Belém dispõe de maiores condições de arrecadação de recursos próprios, o que não ocorre na maior parte dos municípios. Todavia, recursos decorrentes do PAR representaram muito pouco no cômputo geral, sendo o máximo de 3,1\% dos investimentos em educação de Barcarena e o mínimo percentual em Belém de 1,5\% sobre o total e representam a média de 2,5\% em relação às despesas da Função educação no período.

A qualidade da educação não pode prescindir de recursos suficientes para ampliar o investimento em condições para que se torne efetiva. Nesse aspecto, a complementação da União ao FUNDEB tem mais impacto no volume de recursos dos municípios estudados, à exceção de Belém. Todavia, o Estado do Pará ao longo da existência do FUNDEF e do FUNDEB sempre recebeu complementação da União para alcançar o mínimo nacional. E o mínimo nacional não corresponde a um valor compatível com uma educação de qualidade sequer 
inicial, o que se espera aconteça com a implementação do novo Plano Nacional de Educação e a sinalização de aplicação de $10 \%$ do PIB no financiamento da educação.

\section{CONCLUSÕES}

A lógica ou pressupostos da política de financiamento da educação são os mesmos que nortearam um conjunto de reformas no âmbito das políticas sociais, a partir de meados dos anos 1990 do século passado, qual seja: descentralizar a execução de ações e de programas do governo federal para os governos municipais numa relação que, em geral, obnubila o Estado, e, oportunamente, garante espaço à iniciativa privada, apoiando-se na falácia de universalização do atendimento. Verificamos que os cinco municípios que aderiram ao PAR não contaram com aumento substancial de recursos. No cômputo geral da composição de suas despesas com educação, os recursos oriundos do PAR são relativamente baixos e apenas um município alcançou pouco mais de 3\%, tendo a média, de 2010 a 2014, correspondido a 2,5\%. Nesse aspecto, o regime de colaboração a partir do PAR representa mais um caso ilustrativo dessa lógica que vem norteando a política de financiamento da educação, qual seja, multiplicar as ações a partir das mesmas fontes de receitas existentes, assentada em programas muito bem articulados baseados no pressuposto de que problemas relativos à qualidade da educação não demandam ampliação de recursos, mas apenas planejamento e gestão, mantendose assim as assimetrias na capacidade de provimento das políticas educacionais.

\section{REFERÊNCIAS}

ABRUCIO, Fernando Luiz. A dinâmica Federativa da Educação brasileira: diagnóstico e propostas de aperfeiçoamento. In: OLIVEIRA, Romualdo e SANTANA, Wagner. Educação e Federalismo no Brasil: combater as desigualdades, garantir a diversidade. Brasília: UNESCO, 2010.

AFFONSO, Rui. A federação no Brasil: impasses e perspectivas. In: AFFONSO, Rui de Britto Alvares \& SILVA, Pedro Luiz Barros (Orgs.). Descentralização e Políticas Sociais. São Paulo: FUNDAP, 1995.

AMARAL, Nelson C. O Fundeb em uma perspectiva comparada com o financiamento da educação básica nos países da OCDE e do BRICS. Em Aberto, Brasília, n.93, p.63-83, 2015. 
BRASIL. Lei $\mathbf{n}^{\mathbf{0}} \mathbf{1 2 . 6 9 5}$ de 25 de julho de 2012. Dispõe sobre o apoio técnico ou financeiro da União no âmbito do Plano de Ações Articuladas. Disponível em: http://www.planalto.gov.br/ccivil_03/_Ato2011-2014/2012/Lei/L12695.htm. Acesso em 22 de fev. 2016.

BRASIL. Decreto $\mathbf{n}^{\mathbf{0}} \mathbf{6 . 0 9 4}$ de 24/04/2007. Dispõe sobre a implementação do Plano de Metas Compromisso Todos pela Educação, pela União Federal, em regime de colaboração com Municípios, Distrito Federal e Estados, e a participação das famílias e da comunidade, mediante programas e ações de assistência técnica e financeira, visando a mobilização social pela melhoria da qualidade da educação básica. Disponível em: http://www.planalto.gov.br/ccivil_03/_Ato20112014/2012/Lei/L12695.htm. Acesso em 22 de fev. 2016.

- EC n ${ }^{\circ}$ 53, de 20 de Dezembro de 2006. Modifica os Art. 7º 23, 30, 206, 208, 211 e 212 da Constituição Federal e dá nova providência ao Art. 60 do Ato das Disposições Constitucionais Transitórias. Brasília: Diário Oficial da União, de 20 de dezembro de 2006. WWW.planalto.gov.br/cccivil Acesso em: $16 / 01 / 2014$.

. Emenda Constitucional n. 14, de 12 de setembro de 1996. Disponível em: http://www.planalto.gov.br. Acesso em 22/11/13.

Constituição da República Federativa do Brasil. Diário Oficial da União. Brasília: Imprensa Nacional, 1988;

BREMAEKER, F.E.J. Despesas municipais com as funções de competência da União e dos Estados. Série Estudos Especiais, n 49. Rio de Janeiro: IBAM, 2003. (Ele é documento único)

CAMINI,Lucia. A Política Educacional do PDE e do Plano de Metas Compromisso Todos pela Educação. In: RBPE, v. 26, no 3, p.535-550, set.dez./2010.

CASTRO, Jorge Abrahão de. Dilemas para o Financiamento da Educação. In; CUNHA, C. GADOT'TI, M. BORDIGNON, G. NOGUEIRA, F. (orgs). O Sistema Nacional de Educação. Diversos olhares 80 anos após o Manifesto. MEC/UNESCO, 2014, pp.178-196.

FARENZENA, Nalu. A política de financiamento da educação básica: rumos da legislação brasileira. Porto Alegre: Editora da UFRGS, 2006. 
GEMAQUE, Rosana. M. O. Financiamento da educação: O FUNDEF na educação do estado do Pará: feitos e fetiches. 2004. 372 f. Tese (Doutorado em Educação) - Universidade de São Paulo, São Paulo, 2004.

GUTIERRES, Dalva Valente Guimarães. A municipalização do ensino no município de Altamira/PA e suas implicações para a democratização educacional. 2010. 367 f Tese (Doutorado em Educação) - Universidade Federal do Rio Grande do Sul. Porto Alegre, 2010.

OLIVEIRA, Romualdo; SANTANA, Wagner. Educação e Federalismo no Brasil: combater as desigualdades, garantir a diversidade. Brasília: UNESCO, 2010.

PARÁ. Estatística Municipal de Barcarena, 2014. Disponível em: www.idesp. pa.gov.br. Acesso em novembro de 2015.

PINTO, José Marcelino de Rezende. O Fundeb na perspectiva do custo-aluno qualidade. Em Aberto, INEP/MEC -Brasília: n.93, pp.101-117, 2015.

REZENDE, Fernando. Federalismo fiscal: em busca de um novo modelo. In: OLIVEIRA, Romualdo P.; SANTANA, W. (Orgs). Educação e federalismo no Brasil: combater as desigualdades, garantir a diversidade. - Brasília: UNESCO, 2010. p. 71-88. Disponível em: http://unesdoc.unesco.org/ images/0018/001873/187336por.pdf. Acesso em agosto de 2015.

SAVIANI, Dermeval. O Plano de Desenvolvimento da Educação: análise do Projeto do MEC. Educ. Soc., Campinas, v. 28, n. 100 - Especial, p. 1231-1255, out. 2007.

SOUZA, Celina. Federalismo: teorias e conceitos revisitados. In: BIB, São Paulo, $\mathrm{n}^{\mathrm{o}} 65$, pp. $27-48,1^{\circ}$ semestre de 2008.

Sites consultados:

http://www.tcm.pa.gov.br

http://www.fnde.gov.br/pls/edw fnde/internet fnde.LIBERACOES 01 PC?p ano $=2015 \&$ p programa $=C 7 \& p$ uf $=P B \& p$ municipio $=120170$ 
www.fnde.gov.br/siope/relatoriosMunicipais.jsp

https://www.fnde.gov.br/siope/relatorioRREOMunicipal2006.do

https://www.fnde.gov.br/siope/demonstrativoFuncaoEducacao.do

https://www.fnde.gov.br/siope/demonstrativoFundefMunicipal.do

www.idesp.pa.gov.br

DALVA VALENTE GUIMARÃES GUTIERRES é doutora em Educação pela Universidade Federal do Rio Grande do Sul (UFRGS) - 2010. Professora e Pesquisadora vinculada ao Instituto de Ciências da Educação e ao Programa de Pós-Graduação em Educação - PPGED da Universidade Federal do Pará, Campus Universitário de Belém. E-mail: dalva.valente@gmail.com

ROSANA MARIA GEMAQUE ROLIM é doutora em Educação pela Universidade de São Paulo (USP) - 2004. Professora e Pesquisadora vinculada ao do Instituto de Ciências da Educação e ao Programa de Pós-Graduação em Educação PPGED da Universidade Federal do Pará, Campus Universitário de Belém. E-mail: rgemaque@uol.com.br 